\title{
The effect of treadmill gait training with patellar taping on gait abilities in chronic stroke patients
}

\author{
Jin Shin ${ }^{\mathrm{a}}$, Yijung Chung ${ }^{\mathrm{b}}$ \\ ${ }^{a}$ Department of Physical Theraphy, The Graduate School, Sahmyook University, Seoul, Republic of Korea \\ ${ }^{b}$ Department of Physical Thearpy, College of Health and Wealfare, Sahmyook University, Seoul, Republic of Korea
}

\begin{abstract}
Objective: The purpose of this study is to investigate the effect of treadmill gait training with patellar taping on gait abilities in chronic stroke patients.

Design: Randomized controlled trial.

Methods: Thirty chronic stroke patients who have been diagnosed at least six months or before were recruited in Gyeongin Rehabilitation Center Hospital, located in Incheon. Patients who were enrolled in this study were randomized to experimental group $(n=15)$ or control group $(n=15)$. Treadmill with patella taping training group patients were applied with patellar taping when they were being trained on a treadmill. Control group patients were being trained on a treadmill without any kind of taping. Gait parameters were measured with a GAITRite ${ }^{\mathbb{R}}$ system which evaluated gait performances. Gait trainings were done for $30 \mathrm{~min} /$ day, 5 days/week, for 4 weeks.

Results: After treadmill training, treadmill with patella taping training group showed a significant improvement in gait abilities, including velocity, cadence, paretic and non-paretic step length, and double support period $(p<0.05)$. However, in general treadmill group, there were no significant differences in gait parameters except velocity and cadence. There was a significant difference in gait performance in the experimental group compared with the control group, except for the gait symmetry ratio $(p<0.05)$.

Conclusions: According to this result of this study, it seems that application of patellar taping in treadmill gait training for chronic stroke patients significantly improved gait abilities of these patients. Also, we can conclude that patella taping is thought to be useful in real clinical settings where there are many chronic patients who are in need of improvement in their gait abilities.
\end{abstract}

Key Words: Athletic tape, Gait, Patella, Stroke

\section{Introduction}

Stroke is thought to be a serious health problem which can cause severe disabilities. Aspects of disabilities caused by stroke are various according to the affected region and its severity. In general, sensory deficits, cognitive problem, motor impairment, visual perceptual disorders and dysphagia mainly occur among stroke patients [1,2]. In particular, gait disturbance is induced by disabilities in muscle weakness, abnormal muscle contraction, or postural control. This gait disturbance is exhibited as an asymmetric gait pattern, such as a decrease in paretic side stance phase and non-pa- retic swing phase, cadence, velocity and difference in step length and stride length. Therefore, these differences create abnormal gait patterns in stroke patients [3]. Furthermore, gait disturbance has an unfavourable effect on functional independence and prognosis of patients. Due to this reason, recovery in gait ability of stroke patients is considered as a very important goal in rehabilitation [4-6].

For improving gait ability in stroke patients, various studies have been conducted. They include visual feedback training [7,8], dynamic balance control training [9], body weight shift control training [10,11], motor learning [12], task oriented training [13], Tai-chi program [14], and vir-

Received: 6 November, 2015 Revised: 19 November, 2015 Accepted: 23 November, 2015

Corresponding author: Yijung Chung

DDepartment of Physical Thearpy, College of Health and Wealfare, Sahmyook University, 815 Hwarang-ro, Nowon-gu, Seoul 01795, Republic of Korea Tel: 82-2-3399-1637 Fax: 82-2-3399-1639 E-mail: yijung36@syu.ac.kr

(c) This is an Open-Access article distributed under the terms of the Creative Commons Attribution Non-Commercial License (http://creativecommons.org/licens es/by-nc/4.0) which permits unrestricted non-commercial use, distribution, and reproduction in any medium, provided the original work is properly cited.

Copyright $@ 2015$ Korean Academy of Physical Therapy Rehabilitation Science 
tual-reality training [15]. Each of these studies has confirmed the effect of gait training in stroke patients.

Recently, treadmill gait training is frequently used as a therapeutic approach to improve gait patterns of stroke patients within the clinic [16-18]. Also, treadmill gait training is used for rehabilitation of stroke patients or patients who have gait disturbances clinically [19]. Treadmill gait training enables patients to perform symmetric gait as they support their body weight. Also, stroke patients can improve their gait abilities by decreasing their spasticity level during treadmill gait training [20].

Many studies have proven the effectiveness of taping in solving gait problems in stroke patients. Taping helps to protect and support joints while they perform functional movement [21]. Taping can also help increase kinetic stability of movement [22]. According to previous studies on taping in post-stroke patients, during the stance phase gait, application of gluteal taping resulted in improvement in hip joint extension [23]. In addition, kinesio-taping ${ }^{\mathbb{R}}$ performed on stroke patients was reported to improve bio-electrical activation of the vastus medialis [24].

A majority of stroke patients present with tightness in the gastrocnemius muscle and weakness in the gluteus medius muscle on the affected side. Gastrocnemius tightness may limit ankle dorsiflexion, which can result in increased subtalar joint pronation and tibial internal rotation, contributing to abnormal pulling of the patellar tendon and the patellar malalignment [25]. Dysfunction of the gluteus medius muscle may induce excessive internal rotation at the hip. Increased internal rotation of the hip can contribute to a greater valgus force vector at the knee, thus resulting in patellar malalignment [26]. To ensure functional efficacy of patients, maintaining the patellar alignment in the trochlear groove of the femur is necessary [27]. Patellar taping effectively realigns the location of the patella. McConnell [28] introduced a rehabilitation program that incorporates patellar taping techniques to improve patellar tracking within the patellofemoral groove, as well as stretching of the lateral knee soft tissues, vastus medialis oblique strengthening, and closed kinetic chain training.

However, up to date, there has been a lack of studies for gait ability of hemiplegic stroke patient who have undergone the intervention of treadmill training with taping. In particular, application of taping the patella and its effect on gait patterns in hemiplegic patients is very rare. Therefore, in this study, the effect of patellar taping on gait ability in chronic stroke patients undergoing treadmill gait training was investigated. We hypothesized that spatiotemporal gait parameters and gait symmetry would be much more enhanced in treadmill gait training with patellar taping than that in general treadmill gait training. This study further attempted to provide more improved clinical therapeutic techniques for chronic stroke patients.

\section{Methods}

\section{Subjects}

Thirty stroke patients who were hospitalized in Gyeongin Rehabilitation Center Hospital in Incheon were recruited. These patients were divided randomly into two groups (patellar taping treadmill group, general treadmill group). Study duration was from July 2015 to August 2015 and the inclusion criteria of the patients was followes; hemiplegia patients who were diagnosed with stroke 6 months ago or longer, patients who can walk independently on a treadmill gait with hand support; patients who had neither hemianopia nor dysopsia and patients who had a Mini-Mental State Examination-Korean (MMSE-K) score of more than 21; Informed consent was voluntarily obtained from all patients before participation in the study.

\section{Procedures}

This study was conducted as a pre- and post-test (Figure 1). Thirty chronic stroke patients who were matched with the inclusion criteria were randomized into the patellar taping treadmill group (15 patients) or general treadmill group (15 patients). The patients were divided randomly into two groups (patellar taping treadmill group, general treadmill group) by an independent person through random selection of sealed envelopes before the start of the intervention. The patellar taping treadmill group applied patellar taping on their knee joints and then performed gait training on a treadmill. The general treadmill group performed conventional gait training on a treadmill. As a pre-test, gait parameters such as velocity, cadence, paretic/non-paretic step length, double support period, and gait symmetry ratio of patients were measured. Patellar taping treadmill group gait training was performed for $30 \mathrm{~min} /$ day each, 5 days/week, for 4 weeks. After the end of the gait training, a post-test was done as in same manner of the pre-test. Baseline and outcome data of this study were measured by two physical therapists. To control for bias of the subjects, a single blind method was used.

In the patellar taping treadmill group, non-elastic Endura- 


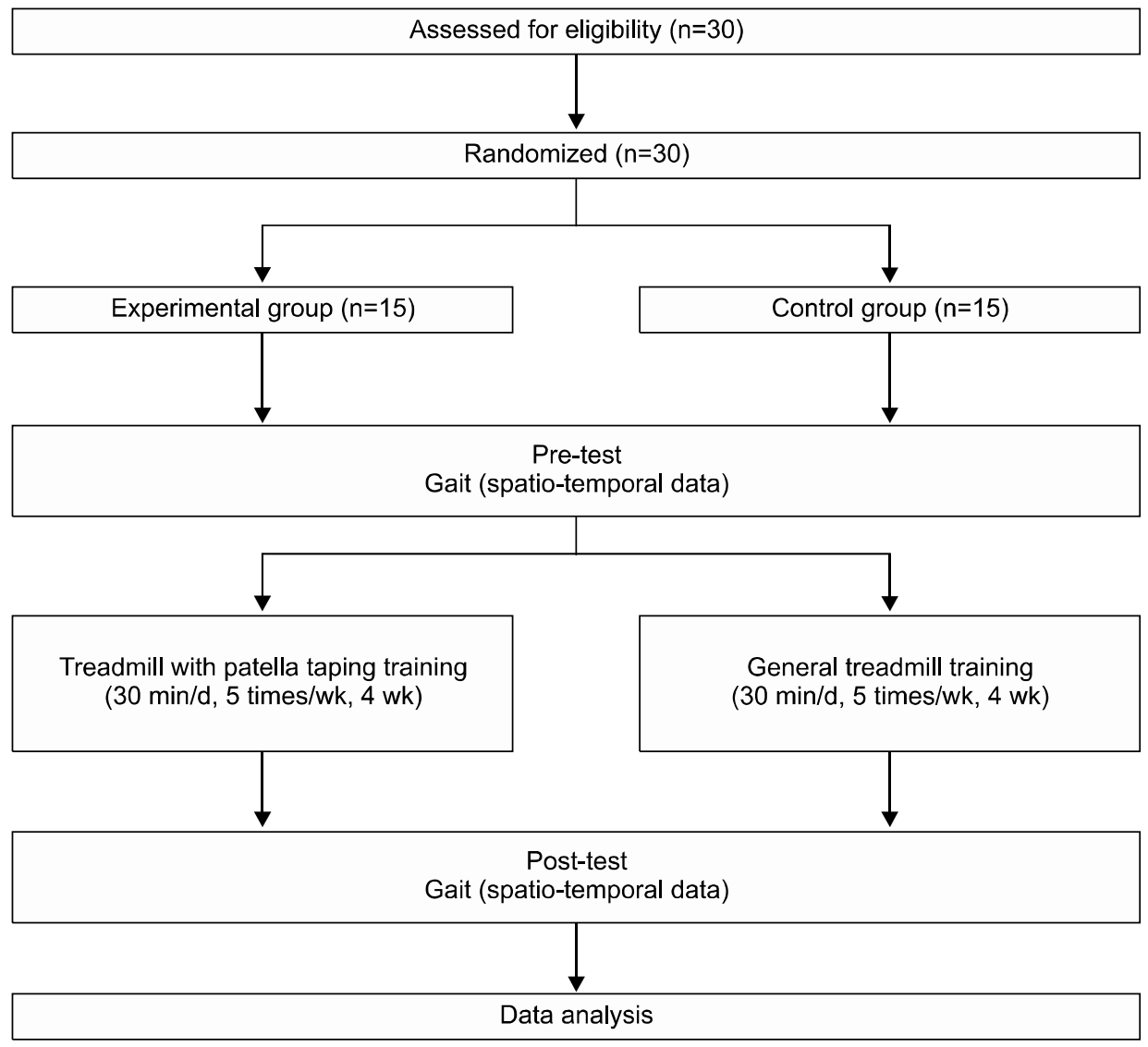

Figure 1. Flow diagram of total experimental procedure.
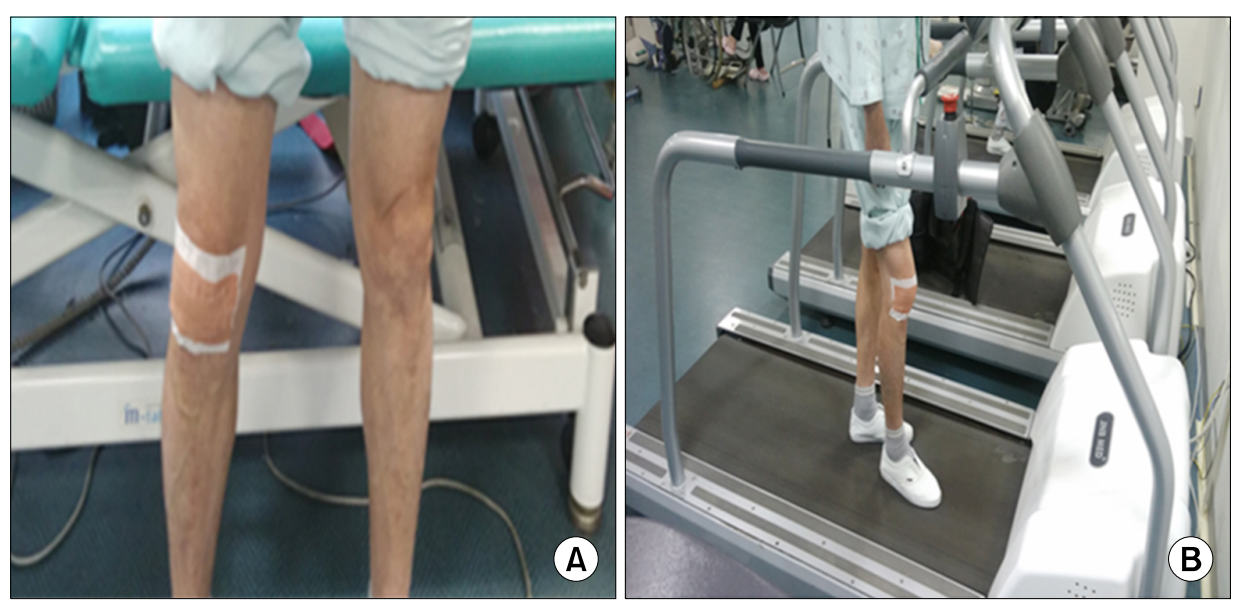

Figure 2. (A) Patellar taping. (B) Gait training with patellar taping.

sports tape (OPTP, Minneapolis, MN, USA) and elastic Endura-fix tape (OPTP) were used for patellar- intervention. To apply McConnell taping [28], the patella was pushed toward the inside to induce medial attraction, and then was fixated with the tape. Endura-sport tape and Endura-fix tape was used for patellar tape. Fixing was done with the patella tucked in according to the method used by Pfeiffer et al. [29]. To prevent the skin from sliding, Endura-sport tape was attached on the region where the Endura-fix tape was attached. In the general treadmill group, the subjects performed gait training for 30 minutes/day each, 5 days/week, for 4 weeks without taping. The mode of pre-test and post-test of the general treadmill group was identical to that of the patellar taping treadmill group. Before treadmill gait training, a comfortable speed of each subject was evaluated using GAITRite ${ }^{\circledR}$ (CIR System Inc., Sparta, NJ, USA), and 
was re-tested every week. Gait training was performed using a comfortable speed. Treadmill speed was increased by 0.1 $\mathrm{km} / \mathrm{h}$ each time once the participants could walk stably for more than 20 seconds [30,31]. All subjects who used a treadmill wore a suspension device for safety purposes. To prevent falls during training, the therapist stood beside the patient and the patient was allowed to grab the handrails but was discouraged from using them to assist in weight support (Figure 2).

This study utilized GAITRite ${ }^{\circledR}$ to measure the gait element of subject patients. For gait factor, temporal and spatial factors (velocity, cadence, paretic \& non-paretic step length, double support period, gait symmetry ratio) of the patellar taping treadmill group were analyzed and compared to the that of the general treadmill group. The gait symmetry ratio is a 'paretic gait cycle ratio (paretic swing time/paretic stance time) divided by the non-paretic gait cycle ratio (non-paretic swing time/non-paretic stance time' (Figure 3).

In the GAITRite ${ }^{\circledR}$ system, all gait within the correlation coefficient were more than 0.96 at comfort gait velocity state [32]. For gait characteristic measurements, excellent coreelation was confirmed between measurement by using paper-and-pencil (intraclass correlation coefficient $[\mathrm{ICC}]=0.95$ ) and measurements by using video-based motion analysis $(\mathrm{ICC}=0.94)$ [33].

\section{Data and statistical analysis}

Statistical analyses were conducted using the SPSS ver. 12.0 (SPSS Inc., Chicago, IL, USA). Normality test of variables was conducted by the Shapiro-Wilk test and $\chi^{2}$ test was carried out for homogeneity test between groups. Betweengroup comparisons of the changes between the pre-test and post-test were performed using the paired t-test, Within- group comparisons were performed using the independent t-test. Statistical significance was established as $p<0.05$.

\section{Results}

\section{Baseline characteristics}

General characteristics of subjects are as follows (Table 1). No significant differences were evident between the patellar taping and general treadmill groups in baseline characteristics.

\section{Spatiotemporal gait parameters}

Changes in gait parameters before and after treadmill gait training with patellar taping are listed in Table 2.

In both groups, there was a significant difference in gait velocity between pre and post intervention $(p<0.05)$. For gait velocity change in pre-post gait training, changes in the patellar taping treadmill group was $-31.16(23.28) \mathrm{cm} / \mathrm{sec}$; in the general treadmill group, the change was -8.82 (7.50) $\mathrm{cm} / \mathrm{sec}$. There was a significant difference between the two groups $(p<0.05)$ (Figure 4$)$.

In both groups, cadence was significantly increased $(p<0.05)$. For cadence changes in pre-post gait training, changes in the patellar taping treadmill group was -22.26 (23.19) steps/min and for the general treadmill group, the change was $-7.19(11.85) \mathrm{steps} / \mathrm{min}$. There was a significant difference between the two groups $(p<0.05)$ (Figure 5).

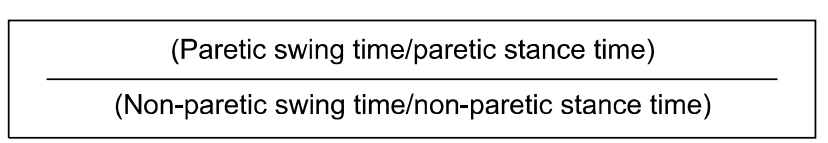

Figure 3. Formula of gait symmetry ratio.

Table 1. General characteristics of the subjects

$(\mathrm{N}=30)$

\begin{tabular}{lccr}
\hline & $\begin{array}{c}\text { Treadmill with patella taping } \\
\text { training group }(\mathrm{n}=15)\end{array}$ & $\begin{array}{c}\text { General treadmill group } \\
(\mathrm{n}=15)\end{array}$ & $\chi^{2 / \mathrm{t}(p)}$ \\
\hline Sex (male/female) & $12 / 3(80.0 / 20.0)$ & $10 / 5(66.7 / 33.3)$ & $0.682(0.409)$ \\
Paretic side (right/left) & $8 / 7(53.3 / 46.7)$ & $7 / 8(46.7 / 53.8)$ & $0.133(0.715)$ \\
Etiology (infarction/hemorrhage) & $10 / 5(66.7 / 33.3)$ & $12 / 3(80.0 / 20.0)$ & $0.682(0.715)$ \\
Height (cm) & $169.26(7.92)$ & $164.21(9.35)$ & $1.595(0.122)$ \\
Age (yr) & $56.20(13.67)$ & $48.93(10.44)$ & $-0.514(0.113)$ \\
Post-stroke duration (mo) & $9.60(2.30)$ & $10.41(2.79)$ & $-0.447(0.655)$ \\
Brunnstrom stages (score) & $3.85(0.69)$ & $3.57(0.78)$ & $-0.835(0.404)$ \\
MMSE (score) & $26.71(2.13)$ & $26.14(1.95)$ & $-0.519(0.604)$ \\
\hline
\end{tabular}

Values are presented as $\mathrm{n}(\%)$ or mean (SD).

MMSE: mini-mental state examination. 
Table 2. Comparison of gait parameters within and between the groups $(\mathrm{N}=30)$

\begin{tabular}{|c|c|c|c|c|}
\hline & & $\begin{array}{l}\text { Treadmill with patella taping } \\
\text { training group }(\mathrm{n}=15)\end{array}$ & $\begin{array}{l}\text { General treadmill group } \\
\qquad(\mathrm{n}=15)\end{array}$ & $\mathrm{t}(p)$ \\
\hline \multirow[t]{4}{*}{ Velocity $(\mathrm{cm} / \mathrm{s})$} & Pre-test & $35.73(22.55)$ & $39.77(19.94)$ & $0.484(0.633)$ \\
\hline & Post-test & $66.90(30.34)$ & $48.60(22.08)$ & \\
\hline & changes & $-31.16(23.28)$ & $-8.82(7.50)$ & $-3.293\left(0.005^{*}\right)$ \\
\hline & $\mathrm{t}(p)$ & $4.827\left(0.001^{*}\right)$ & $4.24\left(0.001^{*}\right)$ & \\
\hline \multirow[t]{4}{*}{ Cadence (steps/min) } & Pre-test & $60.19(19.90)$ & $70.25(27.96)$ & $1.057(0.301)$ \\
\hline & Post-test & 82.45 (20.12) & 77.44 (21.92) & \\
\hline & changes & $-22.26(23.19)$ & $-7.19(11.85)$ & $-2.290\left(0.035^{*}\right)$ \\
\hline & $\mathrm{t}(p)$ & $3.561\left(0.005^{*}\right)$ & $2.187\left(0.049^{*}\right)$ & \\
\hline \multirow[t]{4}{*}{ P-Step length $(\mathrm{cm})$} & Pre-test & $37.06(11.36)$ & $35.23(7.36)$ & $-1.486(0.631)$ \\
\hline & Post-test & $48.84(12.16)$ & $37.79(10.41)$ & \\
\hline & changes & $-11.78(8.23)$ & $-2.55(7.72)$ & $-2.947\left(0.007^{*}\right)$ \\
\hline & $\mathrm{t}(p)$ & $5.160\left(0.000^{*}\right)$ & $1.195(0.255)$ & \\
\hline \multirow[t]{4}{*}{ N-Step length $(\mathrm{cm})$} & Pre-test & $29.71(14.23)$ & $31.77(8.52)$ & $0.447(0.659)$ \\
\hline & Post-test & $45.06(14.63)$ & $35.55(9.83)$ & \\
\hline & changes & $-15.34(10.86)$ & $-3.78(6.90)$ & $-3.238\left(0.004^{*}\right)$ \\
\hline & $\mathrm{t}(p)$ & $5.094\left(0.000^{*}\right)$ & $1.977(0.071)$ & \\
\hline \multirow{4}{*}{$\begin{array}{l}\text { Double support period } \\
\text { (\%cycle) }\end{array}$} & Pre-test & $43.50(14.23)$ & $41.54(11.23)$ & $-0.384(0.704)$ \\
\hline & Post-test & $30.86(9.36)$ & $38.66(10.74)$ & \\
\hline & changes & $12.64(7.34)$ & $2.88(5.53)$ & $3.826\left(0.001^{*}\right)$ \\
\hline & $\mathrm{t}(p)$ & $-6.205\left(0.000^{*}\right)$ & $-1.879(0.085)$ & \\
\hline \multirow[t]{4}{*}{ Gait symmetry ratio } & Pre-test & $1.51(0.89)$ & $1.37(0.92)$ & $-0.389(0.700)$ \\
\hline & Post-test & $1.33(0.50)$ & $1.35(0.99)$ & \\
\hline & Changes & $-0.18(0.64)$ & $0.018(0.60)$ & $0.521(0.607)$ \\
\hline & $\mathrm{t}(p)$ & $-1.007(0.334)$ & $-.109(0.915)$ & \\
\hline
\end{tabular}

Values are presenterd as mean (SD).

P-Step length: paretic step length, N-Step length: non-paretic step length. ${ }^{*} p<0.05$.

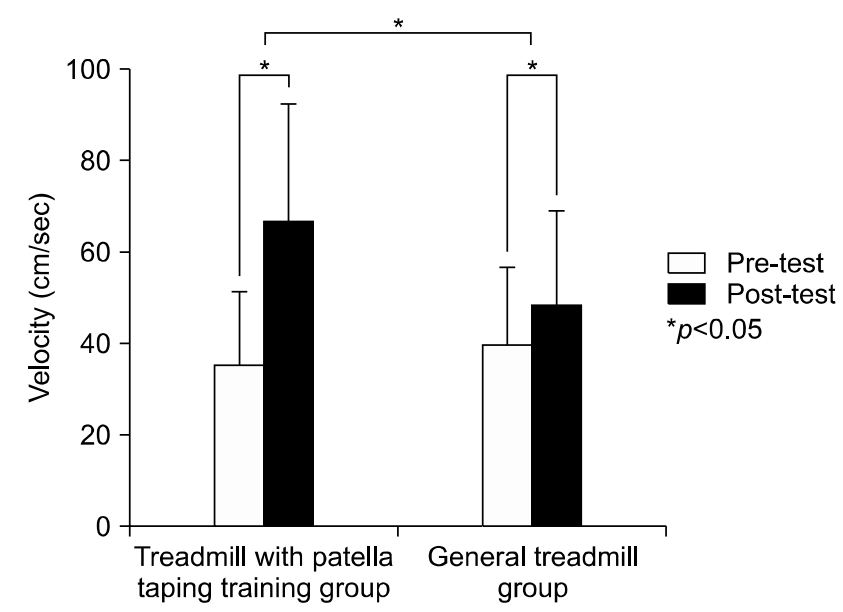

Figure 4. Comparison of velocity.

In the patellar taping treadmill group, paretic step length was significantly increased from 37.06 (11.36) to 48.84 (12.16) $\mathrm{cm}(p<0.05)$. However, in general treadmill group, there was no significant improvement. For paretic step

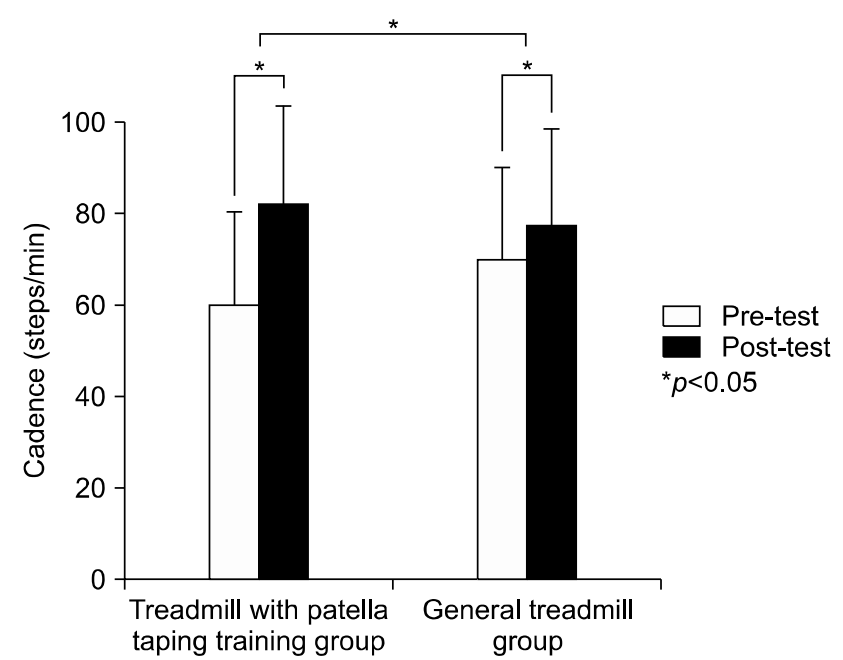

Figure 5. Comparison of cadence.

length changes in pre-post gait training, changes in the patellar taping treadmill group was $-11.78(8.23) \mathrm{cm}$ and for the general treadmill group, the change was -2.55 (7.72) 


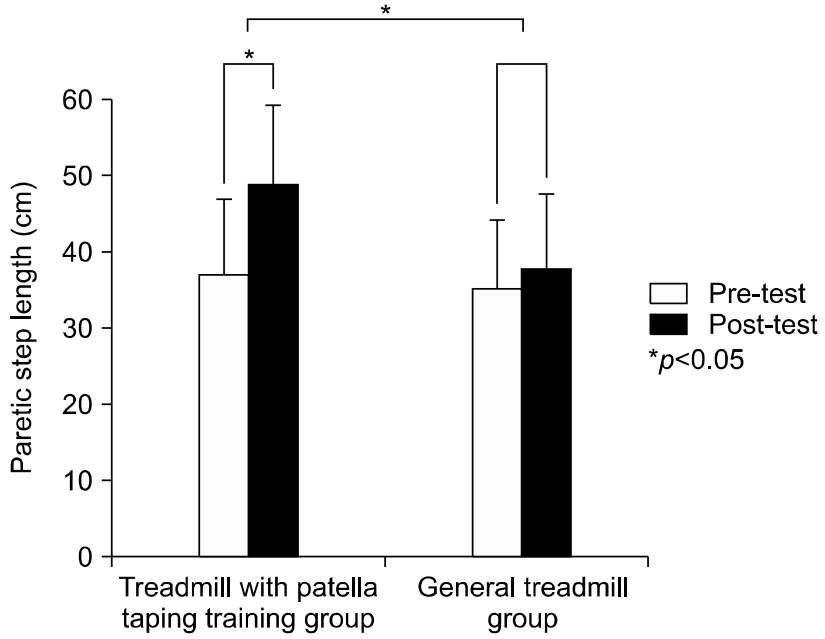

Figure 6. Comparison of paretic step length.

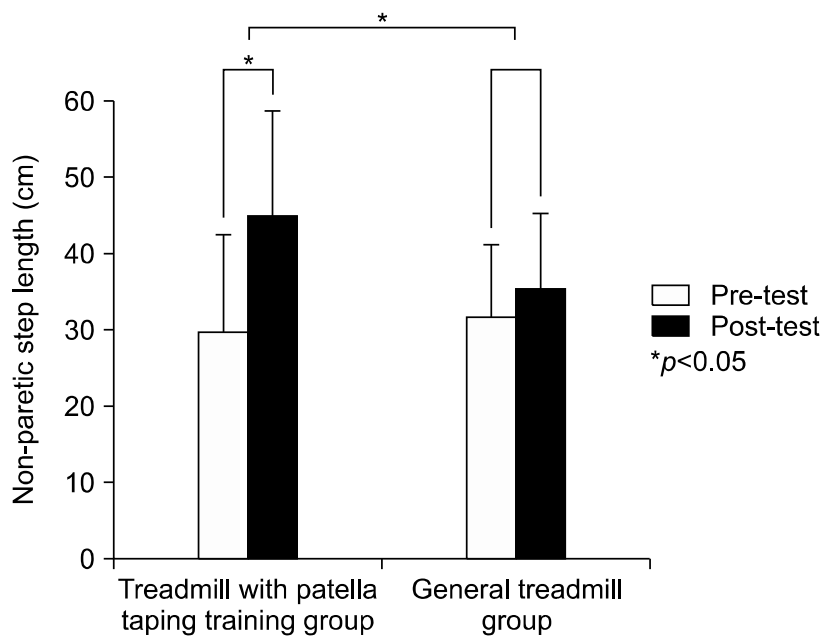

Figure 7. Comparison of non-paretic step length.

$\mathrm{cm}$. There was a significant difference between the two groups $(p<0.05)$ (Figure 6).

In patellar taping treadmill group, the non-paretic step length was significantly increased from 29.71 (14.23) to $45.06(14.63) \mathrm{cm}(p<0.05)$. However, in the general treadmill group, there was no significant improvement. For non-paretic step length changes in pre-post gait training, changes in the patellar taping treadmill group was -15.34 $(10.86) \mathrm{cm}$ and for the general treadmill group, the change was $-3.78(6.90) \mathrm{cm}$. There was a significant difference between the two groups $(p<0.05)$ (Figure 7).

In the patellar taping treadmill group, double support period was significantly decreased from 43.50 (14.23) to 30.86 (9.36) \% cycle $(p<0.05)$. However, in the general treadmill group, there was no significant change. For double support

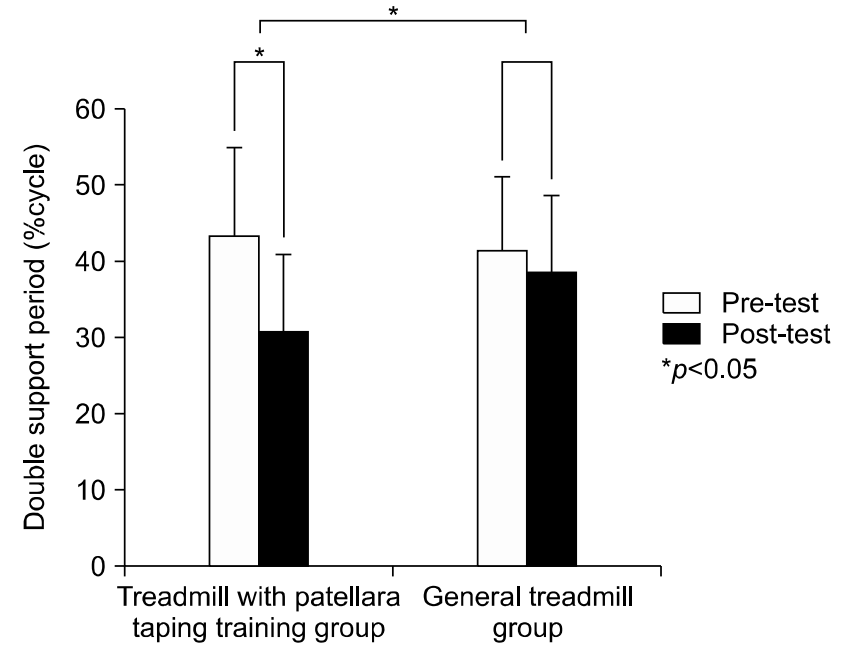

Figure 8. Comparison of double support period.

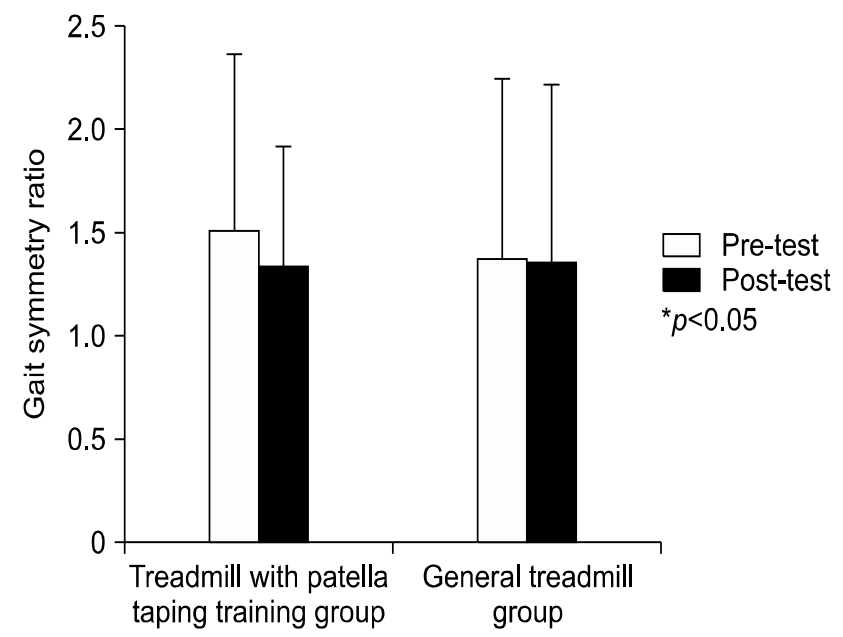

Figure 9. Comparison of gait symmetry ratio.

period changes in pre-post gait training, changes in the patellar taping treadmill group was 12.64 (7.34) \% cycle and for the general treadmill group, the change was 2.88 (5.53) $\%$ cycle. There was a significant difference between the two groups $(p<0.05)$ (Figure 8).

There were no significant changes in gait symmetry ratios in within groups for the pre- and post test and also for between the two groups (Figure 9).

\section{Discussion}

In this study, the effects of treadmill gait training using patellar taping on gait of chronic stroke patient was investigated.

After treadmill gait training, the patellar taping treadmill 
group showed a significant improvement in gait abilities (velocity, cadence, paretic \& non-paretic step length, double support period) $(p<0.05)$. In the general treadmill group, there were no significant differences in gait parameters except for velocity and cadence. Comparison of the patellar taping treadmill group and general treadmill group showed a significant differences in gait performance $(p<0.05)$. Lin et al. [34] reported on gait performance and lower limb's motor function, and the correlation of joint positional sense based on 25 patients. Changes in ankle joint position sense, which led to a significant difference in gait velocity and stride length was reported. Carse et al. [35] conducted a study on 8 patients who were diagnosed with stroke. In this study, the effect of lower limb re-alignment on gait was investigated. The results showed that the walking velocity, overall average step length and cadence were significantly increased from 0.22 to $0.36 \mathrm{~m} / \mathrm{s}, 0.28$ to $0.37 \mathrm{~m}, 45$ to $56 \mathrm{steps} / \mathrm{min}$ respectively.

Patellar taping improves patellar tracking in the patellofemoral groove and not in simple fixation of muscle in clinical settings. This improvement has a positive effect on the patients' gait without pain, re-aligning complete rangeof motion of these patients [29]. McConnell patellar taping method is a taping method which maintain fixed positional fault by repositioning. This method stimulates skin, tendon, and muscle stimulation thus improving joint position sense and proprioception by reducing pain and enhancing recovery of patients. Ernst et al. [36] showed that patellar taping on the knee joint improved the alignment of the patella and stability of the knee joints. Also, patella taping produced beneficial effects on balance ability of the knee joint and function of the lower extremity. In knee osteoarthritic patients, Crossley et al. [37] confirmed that non-elastic taping immediately softened the inflammated tissues and improved the alignment of the lower extremity, thus enhancing their balance ability and physical posture with decreased pain. Usage of patellar taping created pressure on joints, thus providing stability. This re-alignment of the patella and increased stability of the joint region led to improvement in gait ability.

According to Allet et al. [38], asymmetrical weight bearing imposed on stroke patients enhanced control ability in the less affected lower extremity. This led to changes in compensation, thus aggravating asymmetry in gait pattern of stroke patients. In the swing phase of the affected lower limb, decreased muscle power in the lifted foot increased the swing phase time, and this led to a decreased ability in moving weight towards the affected side and decreased affected stance phase term [39]. Therefore, in treating stroke patients, asymmetrical alignment of the lower limb should be considered, and estimation of gait variation to compare asymmetric relationship in gait is very important.

According to gait symmetry ratio result, there was no significant difference between the patellar taping treadmill group and general treadmill group among before and after the treadmill training. Brandstater et al. [40] investigated the relationship between sensory motor impairment and gait asymmetry ratio of stroke patients. He reported that symmetry of both lower extremities in swing phase is related to motor recovery level and there is a significant relationship between Brunnstrom stage and sensory level. Also, Lewek et al. [41] reported a case study based on two chronic stroke patients. In this study, after conducting a proprioceptive feedback program, both patients improved in gait speed and spatiotemporal symmetry. Patellar taping used in this study was a method applied for stability of the knee joint.

Previous studies on general treadmill gait training reported improvements in velocity, cadence, paretic step length, non-paretic step length and double support period after 6 months of treadmill gait training in chronic stroke patients [42]. Also, improvements in velocity, cadence, paretic step length and non-paretic step length were reported after 4 weeks of treadmill gait training in chronic stroke patients who were living in the community [43]. In our study, there was no significant improvement in spatial gait parameters; however, there were similar improvement patterns in these gait parameters to previous studies. Manning and Pomeroy [44] reported that treadmill gait training generally takes from 3 to 13 weeks of training interventions. In conclusion, shorter period (4 weeks) and different patient characteristics (patients who have lower performances in their gait abilities than patients who were living in the community) compared to other studies influenced on different results of this study.

Small sample size of patients and a short duration of 4 weeks occurred as a limitation prevents generalization of the results across all stroke patients. Therefore, a larger sample size of patients and longer duration of the study period are needed to make a generalization over all types of stroke patients and follow-up tests should be made in further studies. This study focused on spatiotemporal gait parameters resulted from gait training with patellar taping. In that sense, further studies which investigates kinematic data of lower extremities in gait training with patellar taping are needed.

In conclusion, patellar taping treadmill gait training significantly increased gait ability of stroke patients. Therefore, 
if patellar taping is applied to stroke patients during treadmill gait training, we can expect improvement in gait ability in those patients.

\section{Conflict of Interest}

The authors declared no potential conflicts of interest with respect to the authorship and/or publication of this article.

\section{References}

1. Mercier L, Audet T, Hébert R, Rochette A, Dubois MF. Impact of motor, cognitive, and perceptual disorders on ability to perform activities of daily living after stroke. Stroke 2001;32:2602-8.

2. Ozdemir F, Birtane M, Tabatabaei R, Ekuklu G, Kokino S. Cognitive evaluation and functional outcome after stroke. Am J Phys Med Rehabil 2001;80:410-5.

3. Dean CM, Richards CL, Malouin F. Walking speed over 10 metres overestimates locomotor capacity after stroke. Clin Rehabil 2001; 15:415-21.

4. Visintin M, Barbeau $H$. The effects of parallel bars, body weight support and speed on the modulation of the locomotor pattern of spastic paretic gait. A preliminary communication. Paraplegia 1994;32:540-53

5. Visintin M, Barbeau H, Korner-Bitensky N, Mayo NE. A new approach to retrain gait in stroke patients through body weight support and treadmill stimulation. Stroke 1998;29:1122-8.

6. Barbeau H, Visintin M. Optimal outcomes obtained with bodyweight support combined with treadmill training in stroke subjects. Arch Phys Med Rehabil 2003;84:1458-65.

7. Yavuzer G, Eser F, Karakus D, Karaoglan B, Stam HJ. The effects of balance training on gait late after stroke: a randomized controlled trial. Clin Rehabil 2006;20:960-9.

8. Srivastava A, Taly AB, Gupta A, Kumar S, Murali T. Post-stroke balance training: role of force platform with visual feedback technique. J Neurol Sci 2009;287:89-93.

9. Worms G, Matjacić Z, Gollee H, Cikajlo I, Goljar N, Hunt KJ. Dynamic balance training with sensory electrical stimulation in chronic stroke patients. Conf Proc IEEE Eng Med Biol Soc 2006;1:2150-3.

10. Dean CM, Channon EF, Hall JM. Sitting training early after stroke improves sitting ability and quality and carries over to standing up but not to walking: a randomised trial. Aust J Physiother 2007;53:97-102.

11. Verheyden G, Nieuwboer A, De Wit L, Thijs V, Dobbelaere J, Devos H, et al. Time course of trunk, arm, leg, and functional recovery after ischemic stroke. Neurorehabil Neural Repair 2008; 22:173-9.

12. Lord SE, Rochester L, Weatherall M, McPherson KM, McNaughton HK. The effect of environment and task on gait parameters after stroke: a randomized comparison of measurement conditions. Arch Phys Med Rehabil 2006;87:967-73.

13. French B, Thomas LH, Leathley MJ, Sutton CJ, McAdam J, Forster A, et al. Repetitive task training for improving functional ability after stroke. Cochrane Database Syst Rev 2007;(4): CD006073.

14. Au-Yeung SS, Hui-Chan CW, Tang JC. Short-form Tai Chi improves standing balance of people with chronic stroke. Neurorehabil Neural Repair 2009;23:515-22.

15. Flynn S, Palma P, Bender A. Feasibility of using the Sony PlayStation 2 gaming platform for an individual poststroke: a case report. J Neurol Phys Ther 2007;31:180-9.

16. Miller EW, Quinn ME, Seddon PG. Body weight support treadmill and overground ambulation training for two patients with chronic disability secondary to stroke. Phys Ther 2002;82:53-61.

17. Ivey FM, Hafer-Macko CE, Macko RF. Task-oriented treadmill exercise training in chronic hemiparetic stroke. J Rehabil Res Dev 2008;45:249-59.

18. Brouwer B, Parvataneni K, Olney SJ. A comparison of gait biomechanics and metabolic requirements of overground and treadmill walking in people with stroke. Clin Biomech (Bristol, Avon) 2009;24:729-34.

19. Hesse S, Bertelt C, Schaffrin A, Malezic M, Mauritz KH. Restoration of gait in nonambulatory hemiparetic patients by treadmill training with partial body-weight support. Arch Phys Med Rehabil 1994;75:1087-93.

20. Hesse S. Locomotor therapy in neurorehabilitation. NeuroRehabilitation 2001;16:133-9.

21. Cools AM, Witvrouw EE, Danneels LA, Cambier DC. Does taping influence electromyographic muscle activity in the scapular rotators in healthy shoulders? Man Ther 2002;7:154-62.

22. McCaw ST, Cerullo JF. Prophylactic ankle stabilizers affect ankle joint kinematics during drop landings. Med Sci Sports Exerc 1999;31:702-7.

23. Kilbreath SL, Perkins S, Crosbie J, McConnell J. Gluteal taping improves hip extension during stance phase of walking following stroke. Aust J Physiother 2006;52:53-6.

24. Słupik A, Dwornik M, Białoszewski D, Zych E. Effect of Kinesio taping on bioelectrical activity of vastus medialis muscle. Preliminary report. Ortop Traumatol Rehabil 2007;9: 644-51.

25. Nyland JA, Ullery LR, Caborn DN. Medial patellar taping changes the peak plantar force location and timing of female basketball players. Gait Posture 2002;15:146-52.

26. Brindle TJ, Mattacola C, McCrory J. Electromyographic changes in the gluteus medius during stair ascent and descent in subjects with anterior knee pain. Knee Surg Sports Traumatol Arthrosc 2003;11:244-51.

27. Aminaka N, Gribble PA. A systematic review of the effects of therapeutic taping on patellofemoral pain syndrome. J Athl Train 2005;40:341-51.

28. McConnell J. The management of chondromalacia patellae: a long term solution. Aust J Physiother 1986;32:215-23.

29. Pfeiffer RP, DeBeliso M, Shea KG, Kelley L, Irmischer B, Harris C. Kinematic MRI assessment of McConnell taping before and after exercise. Am J Sports Med 2004;32:621-8.

30. Yang YR, Tsai MP, Chuang TY, Sung WH, Wang RY. Virtual reality-based training improves community ambulation in individuals with stroke: a randomized controlled trial. Gait Posture 2008;28:201-6.

31. Ditor DS, Kamath MV, MacDonald MJ, Bugaresti J, McCartney N, Hicks AL. Effects of body weight-supported treadmill train- 
ing on heart rate variability and blood pressure variability in individuals with spinal cord injury. J Appl Physiol (1985) 2005;98: 1519-25.

32. van Uden CJ, Besser MP. Test-retest reliability of temporal and spatial gait characteristics measured with an instrumented walkway system (GAITRite). BMC Musculoskelet Disord 2004;5: 13.

33. McDonough AL, Batavia M, Chen FC, Kwon S, Ziai J. The validity and reliability of the GAITRite system's measurements: a preliminary evaluation. Arch Phys Med Rehabil 2001;82:41925.

34. Lin PY, Yang YR, Cheng SJ, Wang RY. The relation between ankle impairments and gait velocity and symmetry in people with stroke. Arch Phys Med Rehabil 2006;87:562-8.

35. Carse B, Bowers R, Meadows BC, Rowe P. The immediate effects of fitting and tuning solid ankle-foot orthoses in early stroke rehabilitation. Prosthet Orthot Int 2015;39:454-62.

36. Ernst GP, Kawaguchi J, Saliba E. Effect of patellar taping on knee kinetics of patients with patellofemoral pain syndrome. J Orthop Sports Phys Ther 1999;29:661-7.

37. Crossley K, Cowan SM, Bennell KL, McConnell J. Patellar taping: is clinical success supported by scientific evidence? Man Ther 2000;5:142-50.

38. Allet L, Leemann B, Guyen E, Murphy L, Monnin D, Herrmann
FR, et al. Effect of different walking aids on walking capacity of patients with poststroke hemiparesis. Arch Phys Med Rehabil 2009;90:1408-13.

39. Patterson KK, Parafianowicz I, Danells CJ, Closson V, Verrier $\mathrm{MC}$, Staines WR, et al. Gait asymmetry in community-ambulating stroke survivors. Arch Phys Med Rehabil 2008;89:304-10.

40. Brandstater ME, de Bruin H, Gowland C, Clark BM. Hemiplegic gait: analysis of temporal variables. Arch Phys Med Rehabil 1983;64:583-7.

41. Lewek MD, Feasel J, Wentz E, Brooks FP Jr, Whitton MC. Use of visual and proprioceptive feedback to improve gait speed and spatiotemporal symmetry following chronic stroke: a case series. Phys Ther 2012;92:748-56.

42. Patterson SL, Rodgers MM, Macko RF, Forrester LW. Effect of treadmill exercise training on spatial and temporal gait parameters in subjects with chronic stroke: a preliminary report. J Rehabil Res Dev 2008;45:221-8.

43. Ada L, Dean CM, Hall JM, Bampton J, Crompton S. A treadmill and overground walking program improves walking in persons residing in the community after stroke: a placebo-controlled, randomized trial. Arch Phys Med Rehabil 2003;84:1486-91.

44. Manning CD, Pomeroy VM. Effectiveness of treadmill retraining on gait of hemiparetic stroke patients; systematic review of current literature. Physiotherapy 2003;89:337-49. 